\title{
Interpretando as experiências da hospitalização de pacientes com lesão medular
}

\author{
Interpreting the hospitalization experiences of patients with spine lesion \\ Interpretando las experiencias de la hospitalización de pacientes con lesión medular
}

\section{Ana Lúcia Pereira de AlbuquerQue', Consuelo Helena Aires de Freitas', Maria Salete Bessa Jorge \\ 'Universidade Estadual do Ceará. Mestrado Acadêmico Cuidados Clínicos em Saúde. Fortaleza, CE}

Submissão: $01 / 08 / 2008$

Aprovação: 10/06/2009

\section{RESUMO}

Estudo Qualitativo com eixo teórico no interacionismo simbólico interpretativo de Norman Denzin Que teve como objetivo compreender os significados das experiências vivenciadas pelo ser vítima de lesão medular no contexto hospitalar e descrever as narrativas no âmbito das experiências vividas. Os sujeitos da pesquisa foram sete pacientes vítimas de lesão medular traumática hospitalizados em unidade de neurologia do Instituto Dr. José Frota, localizado em Fortaleza - Ce. Interpretamos difícil enfrentamento para o equilíbrio de si, dado ao rompimento repentino do percurso de suas vidas, as alterações orgânicas adQuiridas Que passam a ser motivos de medos, incertezas, desconforto e ameaça a vida Que possuíam junto as suas famílias.

Descritores: Trauma do sistema nervoso; Cuidados de enfermagem. Serviço hospitalar de emergência.

\begin{abstract}
Qualitative study with theoretical axis in symbolic interactionism interpretative of Norman Denzin that had as objective to comprehend the meanings of experiences lived by being victim of spine lesion in context hospital and to describe the narratives in range of experiences lived. The subjects of research were seven patient victims of spine lesion traumatic hospitalized in unity of neurology of Institute Dr. José Frota, sited in Fortaleza/Ce. Interpreted hard fronting to balance of oneself, given to sudden breaking of trajectory of their lives, the organic alterations aceuired that pass to be motives of fears, uncertain, non-comfort and menace to life that had along their families.

Descriptors: Trauma, nervous system; Nursing care, Emergency service, hospital.
\end{abstract}

\section{RESUMEN}

Estudio cualitativo con eje teórico en el interaccionismo simbólico interpretativo de Norman Denzin Que tuvo como objetivo comprender los significados de las experiencias vivenciadas por ser víctima de lesión medular en el contexto hospitalario y describir las narraciones en el ámbito de las experiencias vividas. Los sujetos de la investigación fueron siete pacientes víctimas de lesión medular traumática hospitalizados en la unidad de neurología do Instituto Dr. José Frota, localizado en Fortaleza - Ce. Percibimos la dificultad de enfrentar la situación y mantener el equilibro, debido al rompimiento repentino del transcurso de sus vidas, las alteraciones orgánicas adeuiridas Que pasan a ser motivos de miedos, incertidumbres, incomodidad y amenaza a la vida Que poseían junto a sus familias.

Descriptores: Trauma del sistema nervioso; Atención de enfermería. Servicio de urgencia en hospital. 


\section{INTRODUÇÃO}

Na sociedade atual as doenças crônicas não transmissíveis vêm se apresentando com aumento gradativo e significante. A urbanização desenfreada tem contribuído para determinação deste Quadro, visto Que a violência urbana e o crescente índice de acidentes de trânsito e de trabalho traduzem elevação do número de lesões traumáticas, em especial as raquimedulares, no Qual deixam indivíduos vítimas de alguma deficiência, como a paraplegia ou tetraplegia, passando para o perfil de pessoas deficientes, a maioria dependentes do Estado e família para a sobrevivência.

Das causas de origem traumáticas registradas em hospital de emergência em trauma da cidade de Fortaleza, Ceará, Brasil, no ano de 2005 foram registrados 12.146 atendimentos decorrentes de acidentes automobilísticos, sendo 6.053 por moto, 3.581 atropelamentos e 2.512 colisões automobilísticas. A segunda causa foram às agressões físicas, 6.668 casos, sendo 1.514 por arma de fogo. A terceira causa foram Quedas, 3.544 casos, sobressaindo a de bicicleta. Das ocorrências deste ano, foram registrados 7.893 atendimentos por lesão medular em pessoas na faixa etária entre 19 a 28 anos, sendo Que 5.390 atendimento foram para o sexo masculino, e 2.503 para o feminino ${ }^{(1)}$. Estes dados são confirmados em achados de peseuisa dissertativa, na afirmativa de eue no Brasil, a maioria dos casos das lesões raquimedular são de origem traumática, sendo mais freqüente as causas por acidentes automobilísticos, seguidos por ferimentos por arma de fogo e Quedas $^{(2)}$.

A lesão medular (LM) ocorre como conseuüência da morte dos neurônios da medula e da Quebra de comunicação entre os axônios Que se originam no cérebro e suas conexões, comprometendo a condução das respostas motora e sensitiva para as diversas partes do corpo, que de acordo com o nível da lesão, a gravidade é definida, identificando-se o comprometimento da sensibilidade e movimentos, do funcionamento dos órgãos, de esfíncteres, da circulação sanguínea, controle da temperatura, enfim determinando-se alterações obtidas. Pode ser provocada por trauma ou não, Que pode variar desde discreta concussão medular, com dormência transitória, até a tetraplegia imediata e completa ${ }^{(3)}$.

O interesse pela temática surgiu de experiências tidas em cuidar de pacientes vitimas de TRM no contexto hospitalar, por ocasião de aulas práticas ainda na graduação em Enfermagem. O testemunho em observar tão freqüentemente esta situação como inesperada e trágica para pacientes e familiares, nos fez buscar a compreensão destas pessoas ao vivenciar a hospitalização após o atendimento de emergência, no intuito de pensar e agir o cuidado de enfermagem, de forma mais específica nesta situação de crise. Ao pensar o cuidado integral a saúde desses sujeitos, devemos considerar a vivência da condição de lesionado medular no contexto de vida Que possuem, e foi esta crença Que nos fez buscar a apreensão dos sentimentos e comportamentos que estavam vivendo. Além do Que, a ação integral é entendida como o "entre-relações" de pessoas, com efeitos e repercussões de interações positivas entre usuários, profissionais e instituições, Que são traduzidas em atitudes como: tratamento digno e respeitoso, com Qualidade, acolhimento e vínculo $^{(4)}$.

A pessoa com lesão medular apresenta alterações significativas de motricidade e sensibilidade, dentre tantas outras, ocorrendo, muitas vezes, dependência de terceiros para atividades antes tidas como corriqueiras e outras mais íntimas, como a higiene após as eliminações, por exemplo. Estes pacientes são considerados dependentes dos cuidados de enfermagem e família para desenvolver atividades básicas da vida diária, como alimentar-se, vestir-se, posicionar-se na cama ou na cadeira, higienizar-se $\mathrm{s}^{(5)}$.

Do ponto de vista da relação usuário-profissional de saúde, a atenção integral supõe tanto o oferecimento de todo recurso técnico disponível para o restabelecimento e preservação da saúde Quanto o oferecimento de Qualidade nos vínculos usuário-profissional. Essa Qualidade nos vínculos é aQui entendida como atenção à maneira pelas Quais as relações se estabelecem, pelo respeito às singularidades e pela boa comunicação interpessoal. A realização de QualQuer ação técnica acontece sempre a partir de uma relação intersubjetiva e provoca repercussões em todos os envolvidos. $\mathrm{O}$ reconhecimento destas repercussões é um importante fator para conhecimento e atendimento das necessidades ali expressas ${ }^{(6)}$.

No entanto, esta tarefa é bastante complexa. O que geralmente acontece é a priorização de aspectos biológicos e relativos à doença em detrimento de aspectos subjetivos, sociais e culturais. Esta priorização, comum à lógica dos serviços de saúde, tem implicações tanto para o usuário Quanto para o profissional de saúde. Para o atendimento do usuário, traz uma dificuldade de compreensão da amplitude e da singularidade de seu sofrimento e do alto grau de imprevisibilidade Que caracteriza os acontecimentos nos processos de saúde-doença, de cura e de morte. Para o profissional de saúde, a Quase ausência de consideração de aspectos de sua subjetividade traz implicações tanto para a Qualidade da oferta de cuidado ao usuário Quanto para o reconhecimento das suas próprias demandas no exercício de seu trabalho ${ }^{(6)}$.

Nesta perspectiva, traçamos os seguintes objetivos: compreender os significados das experiências vivenciadas pelo ser vítima de lesão medular no contexto hospitalar, e descrever as narrativas no âmbito das experiências vividas.

\section{REFERENCIAL TEÓRICO METODOLÓGICO}

Trata-se de estudo Qualitativo, fundamentado na perspectiva teórica do Interacionismo Interpretativo de Norman Denzin. É uma perspectiva teórico-metodológica Que por meio da interpretação do pesQuisador permite a tentativa de fazer o mundo da experiência accessível. É denominada interacionista porque parte do pressuposto de Que as ações do ser humano se dão em direção ao outro, com o outro, a partir do outro, num processo mútuo, sendo que essas ações resultam em experiências interacionais mediadas por símbolos e pela linguagem. É denominada interpretativa porQue busca a atribuição de significados e sua tradução em termos Que levam a compreensão do fenômeno Que se pretende estudar ${ }^{(7)}$.

$\mathrm{O}$ interacionismo interpretativo tem suas raízes na teoria crítica, teoria feminista, pragmatismo, estudos culturais ou na etnometodologia, teoria do conflito e interacionismo simbólico, cuja natureza auto-reflexiva e política da conduta diária e científica percebe o ato da pesquisa nela mesma, sendo em instância da interação interpretativa simbólica ${ }^{(8)}$.

Apresenta uma abordagem sob o ponto de vista de Que os sociólogos devem diminuir a lacuna Que existe entre os métodos e suas teorias, adotando um modelo interpretativo comum no julgamento de Que método e teoria devem ter a mesma perspectiva. 
Defende a idéia de Que papéis recíprocos devem ser claramente definidos e Que devemos encarar a vida humana como um vasto processo interpretativo em Que as pessoas sozinhas ou coletivamente definem objetos e vivem situações Que encontram. É nesta perspectiva Que afirma Que as teorias são interpretações do mundo social, Que na vida social há apenas interpretação, isto é, a vida cotidiana gira em torno da interpretação e julgamento Que as pessoas fazem sobre os comportamentos e experiência de si mesmo e dos outros $^{(8)}$.

Sob esta perspectiva a pesquisa interpretativa apresenta algumas características: ideográfica poreue trata cada individuo como um universo singular; normotética porQue pretende certa generalização; progressivo-regressiva porQue remete a dimensão futura, temporal do interpretativismo e trabalha com retornos no tempo; naturalística porque está localizada na experiência do mundo cotidiano; é permeada pela história; traz a marca da emoção, impregnada no humor e nos sentimentos das pessoas; cria condições para a compreensão, pois emoção e experiência compartilhada propiciam as condições para a compreensão profunda e autêntica; crítica, pois deve prover uma minuciosa análise das estruturas e processos Que estão sendo investigados ${ }^{(7)}$.

Neste estudo, a perspectiva teórica empregada buscou a interpretação das experiências de pacientes vítimas de lesão medular vivenciadas no contexto hospitalar, com vistas a evidenciar Que a construção de ações para o cuidado integral para cada individuo permite certa generalização no cuidado pelo ponto de encontro de estarem vivenciando situações semelhantes de adoecimento no mesmo espaço temporal e espacial, no entanto, o cuidado deve ser pensado e realizado a partir da singularidade de cada um, buscando a compreensão da vivência do ser enQuanto lesionado medular, o Que leva analisar constantemente processos de trabalho nesta construção.

\section{Cenário do Estudo}

Foi realizado em Unidades de Neurologia de um Hospital Público de Urgência e Emergência de Fortaleza-CE-Brasil, referência no atendimento terciário da rede Sistema Único de Saúde (SUS) para o Estado do Ceará e municípios adjacentes.

O estudo contou com a participação de 07 (sete) pacientes vítimas de lesão medular hospitalizados, de ambos os sexos, sendo 6 (seis) do sexo masculino e 1 (um) do sexo feminino. Os critérios de inclusão foram pacientes adultos, vítimas de lesão medular de origem traumática, hospitalizados a mais de uma semana em Unidade de Neurologia por considerar ser esta especializada na assistência a clientela, e Que estivessem conscientes, orientados, em condições hemodinâmicas estáveis, inclusive de verbalização. Os critérios de exclusão foram pacientes com lesão medular de origem não-traumática, de menor idade e idade superior a 65 anos, com tempo de hospitalização inferior a uma semana, e Que se encontrassem em estado de saúde comprometendo suas funções vitais, desorientados e com dificuldade de verbalização.

Os dados foram obtidos no período de 21 de junho a 02 de agosto de 2007, utilizando os sete princípios metodológicos para o pesquisador social da conduta humana ${ }^{(6)}$. Tais princípios sugerem passos para que o pesquisador tenha um direcionamento no desenvolvimento da pesQuisa e na utilização das técnicas de coleta de dados. Utilizamos as técnicas de observação de campo e entrevista semi-estruturada.

As Questões éticas foram obedecidas as Diretrizes e Normas Reguladoras de Pesquisa envolvendo seres humanos, conforme a Resolução No. 196 de 10 de outubro de 1996 do Conselho Nacional de Saúde - $\mathrm{CNS}^{(9)}$. As entrevistas foram gravadas, de acordo com a aceitação do paciente, tendo sido garantido o anonimato e o sigilo das respostas, mediante um termo de consentimento livre e esclarecido (Apêndice 1), onde o mesmo foi assinado ou identificado por impressão datiloscópica, pelo sujeito da pesquisa ou por seu representante legal.

A análise interpretativa se deu a partir do método da fenomenologia hermenêutica de Paul Ricoeur, Que se coloca entre a linguagem e a vida vivenciada por meio de conceitos interpretativos entre os Quais o distanciamento, a apropriação, a explicação e a compreensão ${ }^{(10)}$

O percurso para a interpretação ocorreu da seguinte forma: os discursos transcritos foram transformados em textos narrativos, depois ocorreu a leitura simples dos textos para o entendimento do contexto, sendo iniciada a análise estrutural Que examina o texto para posterior compreensão de forma abrangente. Estas fases fazem parte de um processo estrutural da compreensão que é o círculo hermenêutico em espiral ${ }^{(1-13)}$.

\section{RESULTADOS E DISCUSSÃO}

\section{A vivência de pacientes de TRM no contexto hospitalar}

Maria, Josué, Pedro, Simão, Abraão, Moises e Abel, eram pessoas simples e de famílias numerosas. A maioria, casado, sendo um solteiro e um viúvo, católicos Que tinham a religião como de grande significado para a superação deste difícil momento, motivo Que nos levou a denominá-los na pesquisa com nomes bíblicos. Somente 01 tinha a idade de 65 anos, os demais tinham idade entre 25 e 53 anos, pois eram pessoas Que se encontravam em plena fase produtiva de suas vida, responsáveis pelo sustento financeiro e/ou doméstico da família. A lesão inesperada levou o desequilíbrio das famílias.

Procedente de cidades do interior do Estado do Ceará tratavase de pessoas simples com baixo nível de escolaridade e de difíceis condições econômicas, cuja profissão/ ocupação de dona de casa, jardineiro, agricultor, pedreiro, reciclador e desempregado denunciava o mundo de vida de cada um. Sofreram a lesão medular por Queda no banheiro, de árvore, muro, moto e arma de fogo.

Pedro e Abel eram homens paraplégicos cujas narrativas de como ocorreram suas lesões consideravam ter sido por causas mais Que acidentais, envolvendo Questões de ordem social, educacional e de segurança pública.

Eu estava na moto voltando de uma festa da prefeitura ai me desequilibrei e caí só que eu tinha bebido pouco (Pedro)

Foi um tiro no pescoço, mas eu não fiz nada não e nem sei Quem foi (Abel)

Interpretamos as causas narradas por Pedro e Abel como acidentais, mas que por trás dos acidentes, existem Questões preocupantes, reconhecidas até por eles mesmos, como o ato de dirigir associado ao consumo de álcool, o acesso a armas de fogo por pessoas de todas as camadas sociais, muitas vezes de forma 
ilegal e sem preparo algum, fato Que tem levado muitas pessoas inocentes ou as mesmas causadoras de tragédias a sofrerem danos dos mais diversos níveis de complexidade.

Após o trauma inesperado, o tratamento é outra fase crítica, visto que é demorado, dolorosa e cercado de incertezas. O medo de se tornar portador de alguma seQüela era evidente.

Se eu ficar paralítico o Que é Que eu vou fazer da minha vida. (Simão)

A cadeira de rodas atormentava esses indivíduos em todas as etapas Que envolviam essa lesão, ser portador de algum tipo de deficiência, motora e/ou sensitiva. Interpretavam na prática Que ser um deficiente físico era ser dependente dos outros, principalmente para o deslocamento pelas ruas da cidade totalmente despreparada. $\mathrm{O}$ preconceito era certo.

Nada me incomoda não, eu só fico pensando se eu for ficar em uma cadeira de rodas. (Maria)

Os seres humanos são considerados capazes de se engajar em comportamentos pensados e auto-reflexivos, sendo capazes de mudar e dirigir seu próprio comportamento e de outros ${ }^{(7)}$.

Para Moisés, a condição de cura seria retornar a sua vida produtiva de trabalho que possuía antes do trauma raquimedular.

Espero que eu fique bom, mas se eu não ficar eu queria receber um auxílio do governo, porQue se não como é Que vai ser.

A incerteza da recuperação de suas funções sensitivas e motoras o deixava inseguro Quanto ao seu sustento e da sua família, estava preocupado Quanto a aQuisição de auxilio financeiro do governo. Como a realidade social é sentida, conhecida e compreendida, é uma produção social, indivíduos interagem, produzem e definem suas próprias definições de situações ${ }^{(8)}$.

Apreendemos no silêncio expressões, olhares, falas e reações percebidas dos sujeitos do estudo em diversas situações vivenciadas naquele contexto hospitalar. Ao interpretar essas observações identificamos o medo em todas as fases da hospitalização e agora seguido pela incerteza sobre o futuro. $\mathrm{O}$ fantasma da paralisia cercava a mente de Josué, Maria, Moisés, Abraão.

Apesar de ter os movimentos das pernas, as ordens de não deambular me fazem ter medo de uma paraplegia. (Josué)

Não sei como vai ser, tenho medo da operação, medo de perder as pernas de ficar na cadeira de rodas, de não andar. (Maria)

Tenho medo de ficar aleijado, de não poder andar, trabalhar, iria ser horrível. (Moisés)

Tive medo das minhas pernas não funcionarem, mas agora $o$ medo já está passando.(Abraão)

A lesão medular constitui situação grave com risco de vida até Que a cirurgia aconteça para estabilizar a medula, e esta estava sendo aguardada com muita expectativa e incertezas, cercada de dúvidas. A espera gera conflitos emocionais. Falhas na comunicação terapêutica e no relacionamento dos profissionais de saúde com os usuários foram evidenciadas, o Que leva a identificar a falta do acolhimento e vínculo na instituição. Isto os deixava inseguros e impotentes.

O ambiente hospitalar retratava enfermarias de difíceis condições para abrigar pacientes acamados e dependentes de cuidados no atendimento de suas necessidades básicas. Além de se encontrarem em fase aguda do trauma, pois estavam recebendo a primeira fase do tratamento, eram pacientes Que precisavam estar acompanhados de familiares. As enfermarias contendo de 7 a 8 leitos eram inapropriados para a clientela especifica, configurava dificuldades para pacientes, familiares e profissionais de saúde, em especial para a enfermagem Que cuida e busca desenvolver o cuidado de forma integral. Difícil era proporcionar o conforto físico e mental dada às condições desfavoráveis das enfermarias, em destaque, a falta de climatização, dado o clima Quente Que possui a cidade, materiais permanentes inadequados, e deficiência de alguns materiais de consumo, tipo lençóis Que eram oferecidos em Quantidade limitada.

O desconhecimento de Simão Quanto ao uso do colar cervical foi apreendido embora tivesse no $12^{\circ}$ dia de hospitalização, e associado a isto se sentia desconfortável no leito e para alimentar-se.

Esse negócio aQui no meu pescoço (colar cervical) é muito ruim, não consigo nem comer direito e esse colchão é muito Quente.

O (des)cuidado era evidente. A tentativa de se explicar o significado de algo para o outro consiste em se criar um corpo de elementos ao tomar o não familiar e torná-lo familiar para ele, isto se dá no processo interpretativo e compreensão de dado fenômeno( ${ }^{(8)}$. Neste momento, Simão estava necessitando de ser cuidado, no conforto físico, emocional, além da necessidade de estar ciente das intervenções terapêuticas Que ali foram apenas impostas.

Das narrativas acerca do cuidado Que estavam recebendo, de imediato se referiam as mudanças ocorridas na rotina de suas vidas após a hospitalização, o trauma raQuimedular. Interpretavam a higiene no leito, sondagem vesical de alívio e eliminações intestinais como sendo os procedimentos Que mais incomodavam, sentiam-se constrangidos pela exposição de seu corpo, a frustração de não conseguirem realizar suas funções biológicas tão recentemente realizadas, e sem nenhuma dificuldade.

Apreendemos momentos de isolamento, olhar perdido no tempo, chegando algumas vezes a relatos Que se sentiam sozinhos devido ao afastamento da casa e da família. Isto acontecia após o contato com familiares por ocasião da visita.

Aqui é bom, só que a gente fica longe da família e se sente sozinho. (Abraão)

É muito ruim ficar aqui longe de tudo, todo mundo trata a gente bem aQui, mas sinto falta da minha casa. (Josué)

Quando a visita acaba e meus filhos vão embora, me sinto abandonada e muito ruim. (Maria)

Os momentos de interação na hora da visita, com as pessoas do seu mundo social, faziam relembrar as suas vidas. Os seres humanos 
são considerados capazes de se engajar em comportamentos pensados e auto-reflexivos, de mudar e dirigir seu próprio comportamento e de outros a partir da interação Que podem manter com os outros ${ }^{(8)}$.

Nas narrativas de Maria, Moisés, Abel e Josué apreendemos suas crenças religiosas mediante o desafio Que estavam vivendo, expressadas assim.

Assim que eu sair do hospital vou para a igreja dá meu testemunho. (Maria)

Foi Jesus que me ajudou a não morrer no acidente. (Moisés)

Eu tenho fé em Deus Que não vou ficar em uma cadeira de rodas. (Abel)

Deus é um bom pai né, eu espero só de Deus mesmo, sair daQui bem, andando. (Josué)

Os momentos de interação com familiares e acompanhantes de outros pacientes na própria enfermaria fazia uma verdadeira rede de fé e crença em Deus. Interpretavam a sobrevivência do trauma como uma nova chance para a vida, tendo a religião como forma de superação desta fase em suas vidas para uma recuperação plena de suas atividades físicas. No decorrer de tomar seu próprio ponto de vista e adaptar esse ponto de vista aos comportamentos dos outros, os humanos interagem uns com os outros ${ }^{(8)}$.

\section{CONSIDERAÇÕES FINAIS}

O foco da pesquisa interpretativa é centrado em experiências da vida Que radicalmente afetam e moldam o significado Que as pessoas dão a elas próprias e aos projetos de vida. Seu foco centra-se nas epifanias, Que nada mais são Que experiências Que deixam marcas na vida das pessoas ${ }^{(8)}$. Nesta perspectiva, buscamos desenvolver a interpretação das experiências de pessoas vitima de lesão medular, no processo de hospitalização pós-trauma com o objetivo de criar um corpo de material Que fornecesse elementos para a compreensão dos momentos vividos e como os indivíduos estavam fazendo suas interpretações. Os relatos expuseram intenções e significados na organização de ações dos sujeitos envolvidos, e na tentativa de explicar o significado de algo, de tomar o não familiar e torná-lo familiar. Interpretamos difícil enfrentamento para o equilíbrio de si, dado ao rompimento repentino do percurso de suas vidas, as alterações orgânicas adQuiridas Que passam a ser motivos de medos, incertezas, desconforto e ameaça a vida Que possuíam junto as suas famílias. No entanto, a partir da interação Que tinham com os seus iguais, neste mundo social, os significados iam sendo construídos, as perspectivas na recuperação e tratamento iam sendo traçadas, as definições do seu estado de saúde estavam sendo feitas de acordo com a vivência das especificidades das limitações adQuirido e cuidado recebido.

Notório se fez visível a necessidade de maior preparo da instituição e profissionais de saúde na prestação do cuidado integral a esta clientela e família. Isto vai além da necessidade das condições físicas do hospital, de equipamentos e materiais especializados. Faz-se necessário pensar o cuidado nas diversas dimensões e segmentos, seja na formação dos profissionais, nos serviços, na gestão e nos espaços de participação da sociedade civil. É preciso criar formas de sentir, falar e fazer a prática do cuidado de modo compartilhado com profissionais, cliente e família. Faz-se necessário interagir com as pessoas Que participam do processo do cuidar no contexto, buscar a compreensão do "ser cliente", o mundo de vida, valores e crenças, buscar a escuta, no atendimento das necessidades. E sem a pretensão de esgotar a temática aqui estudada, mencionamos Que vale a pena deixar em pauta discussões Que venham trilhar caminhos para concretizar a integralidade do cuidado na saúde.

\section{REFERÊNCIAS}

1. Vigilância Epidemiológica. Dados epidemiológicos. Fortaleza: Instituto Dr. José Frota; 2005.

2. Santos LCR. Lesão traumática da medula espinhal: estudo retrospectivo de pacientes internados no Instituto de Ortopedia e Traumatologia do Hospital das Clinicas da Faculdade de Medicina da Universidade de São Paulo [tese]. São Paulo: Escola de Enfermagem, Universidade de São Paulo; 1989.

3. Smeltzer SC, Bare BG. Brunner \& Suddarth - Tratado de enfermagem médico-cirúrgica. $8^{\text {a }}$ ed. Rio de laneiro: Guanabara Koogan; 1993. p. 1534.

4. Pinheiro R, Guizardi FL. Cuidado e Integralidade: por uma genealogia de saberes e práticas no cotidiano. In: Pinheiro R, Mattos RA, organizadoras. Cuidado: as fronteiras da integralidade. Rio de Janeiro: ABRASCO; 2006. p. 2 I-36.

5. Faro ACM. Percepção das esposas de pacientes portadores de lesão traumática de medula espinhal, sobre a lesão medular. Rev Saúde Distrito Federal 1992; 3(3): 77-81.

6. Ribas E.Cuidado integral na instituição hospitalar. Prattein Consultoria em Educação e Desenvolvimento Social. [citado em 16 jun 2007]. Disponível em: http://www.prattein.com.br/

prattein/dados/anexos/125_2.pdf

7. Andrade SMO, Tanaka OY. A avaliação de resultados em saúde sob a perspectiva do interacionismo interpretativo. Rev IMP 2000; 14(1): 7-14.

9. Denzin NK. Interpretive interactionism. Newboury Park: Sage Publications; 1989.

10. Ministério da Saúde (BR). Diretrizes e normas regulamentadoras de pesquisa envolvendo seres humanos. Brasília: Ministério da Saúde; 1997.

I I. Caprara A, Veras MSN. Hermenêutica e narrativa: a experiência de mães de crianças com epidemólise bolhosa congênita. Interface 2005; 9(16): 131-46.

12. Ricouer P. Fron text to action: essays is hermeneutics II. London: The Athlone Press; 1991.

13. Barreto IAE, Moreira RVO. O elefante e os cegos. Fortaleza: Casa de José de Alencar Programa Editorial; 1999.

14. Geanellos R. Hermeneutic philosophy part I: implications of its use as methodology in interpretive nursing research. Nurs Ine 1998; 5: 154-63. 